\title{
A produção do fato da transformação do adolescente: uma análise dos relatórios utilizados na execução da medida socioeducativa de internação
}

\author{
The production of the juvenile's transformation fact: an analysis of the \\ reports used in the execution of detention
}

\section{Bruna Gisi Martins de Almeidab}

Resumo O enquadramento legal definido pelo Estatuto da Criança e do Adolescente para a institucionalização de adolescentes autores de atos infracionais estabelece que a decisão sobre o tempo de duração da internação deve ser produzida ao longo do processo de execução da medida socioeducativa. Partindo de uma pesquisa realizada com as instituições responsáveis pela execução da medida de internação em São Paulo (Fórum Brás e Fundação CASA), o objetivo deste artigo é analisar o processo de construção dessa decisão nos relatórios produzidos pelas equipes técnicas nas unidades de internação para fundamentar a decisão judicial sobre a liberação do adolescente. O contexto prático de elaboração e recepção dos relatórios foi utilizado como esquema interpretativo para análise dos procedimentos empregados para produzir a razoabilidade da decisão de liberar o adolescente da unidade. A análise sugere que os três formatos desses relatos - relatórios inicial, de acompanhamento e conclusivo - exibem organizações típicas e empregam procedimentos que contribuem para a produção do fato da transformação do adolescente como efeito da medida.

Palavras-chave execução de medidas socioeducativas; relatórios; medida de internação; documentos institucionais.

a Este texto apresenta parte dos resultados da pesquisa de doutorado desenvolvida no Programa de Pós-Graduação em Sociologia da Universidade de São Paulo, sob orientação do Prof. Dr. Marcos Alvarez. O trabalho foi realizado com o apoio do CNPq-Brasil e da Fundação de Amparo à Pesquisa do Estado de São Paulo - FAPESP (Processo 2012/25083-3).

b Pesquisadora de Pós-doutorado do Núcleo de Estudos da Violência da Universidade de São Paulo (NEV-USP). Bacharel em Ciências Sociais pela Universidade Federal do Paraná, mestre e doutora em Sociologia pelo Programa de Pós-Graduação em Sociologia da Universidade de São Paulo. 
Aвstract The legal framework defined by the Child and Adolescent Statute for the detention of juvenile offenders stablishes that the decision about the period of institutionalization must be produced during the intervention. Drawing on the results of a research conducted at the organizations responsible for the detention of juveniles in Sao Paulo, this article aims at analyzing the construction of this decision in the reports produced by the institution's staff to support the juridical decision to release the youth. The practical context of the reports' production and reception was used as an interpretive scheme for the analysis of the procedures employed in these accounts to produce the decision of releasing the adolescent as reasonable. The analysis suggests that the three designs of the accounts - initial report; monitoring report and conclusive report - exhibit typical organizations and employ specific procedures that contribute to produce the fact of the juvenile's transformation as a consequence of the intervention.

KEYWORDS execution of interventions; reports; detention of juveniles; institutional documents

Entre as inúmeras inovações que a aprovação do Estatuto da Criança e do Adolescente (BRASIL, 1990) trouxe para a justiça especializada para crianças e adolescentes, a definição do isolamento institucional como privação de liberdade é, sem dúvida, uma das principais. Ao enquadrar essa medida como privação de um direito fundamental, o ECA afirma seu caráter coercitivo e estabelece a necessidade de restringir sua aplicação (cf. Méndez; Carranza, 1992; Méndez, 2006; Machado, 2006; FrASSETO, 2006). Essa perspectiva diverge de modo significativo daquela vigente nas duas legislações que regularam a justiça especializada no Brasil desde a sua emergência: sob os códigos de menores de 1927 e 1979, a institucionalização em estabelecimentos especializados era concebida como medida de proteção para "menores" em estado de abandono moral e material, de prevenção da criminalidade, de correção de "desvios de conduta" e de recuperação de infratores (cf. AlvAREz, 1989; 1996; Rizzini; Rizzini, 2004; ScHUCH, 2005). O isolamento institucional era visto como forma de proteger, corrigir e recuperar os menores por permitir retirá-los do meio causador do crime e do estado de abandono.

Ainda que a proteção de crianças e adolescentes seja definida como a finalidade central do ECA (BRASIL, 1990, Art 10), a institucionalização deixa de ser definida como meio de realização dessa finalidade. Com a aprovação do estatuto, será justamente a restrição da medida de internação que passa a ser afirmada como forma de proteção. A necessidade de proteger o direito individual à liberdade é um dos fatores que contribuiu para outra inovação central promovida pelo estatuto: a distinção 
entre assistência social e repressão às infrações (cf. ScHUCH, 2005; MÉNDEZ, 2006). Entre os dispositivos que limitam o recurso à institucionalização, o ECA diferencia as medidas para crianças e adolescentes cujos direitos foram violados ("medidas de proteção") e aquelas para adolescentes autores de atos infracionais ("medidas socioeducativas") ${ }^{1}$. A medida de internação é definida como medida socioeducativa e, portanto, só pode ser aplicada aos adolescentes que cometeram crimes. Além disso, a institucionalização passa a estar submetida aos princípios da brevidade e da excepcionalidade (BRASIL, 1990, Art. 121), podendo ser utilizada somente como último recurso e pelo menor tempo possível. A excepcionalidade é assegurada na lei pela definição dos casos aos quais a medida se aplica: "I - tratar-se de ato infracional cometido mediante grave ameaça ou violência à pessoa; II - por reiteração no cometimento de outras infrações graves; III - por descumprimento reiterado e injustificável da medida anteriormente imposta" (BRASIL, 1990, Art. 122). Já a brevidade é garantida pelo estabelecimento do limite máximo de duração da internação - três anos para todos os casos (BRASIL, 1990, Art. 121, §3º) - e pela determinação de que a medida seja reavaliada a cada, no máximo, seis meses (BRASIL, 1990, Art. 121, §2º).

A aprovação do ECA significou uma alteração importante na forma de enquadrar legalmente o isolamento institucional de crianças e adolescentes. A internação em instituições especializadas passa a ser definida exclusivamente como resposta ao cometimento de infrações graves ou ao descumprimento reiterado de outras medidas. Há, no entanto, uma dimensão do enquadramento legal da medida socioeducativa de internação que guarda semelhanças com o modelo de justiça especializada estabelecido nos códigos de menores: o modo de determinação do tempo de duração da internação. Assim como nos códigos de menores, o prazo de duração da internação não é determinado no momento de aplicação da medida, mas durante a execução, a partir de avaliações do adolescente. Nesse sentido, é possível dizer que o estatuto mantém o dispositivo das sentenças indeterminadas, destacado pela literatura como uma das características centrais do modelo da justiça especializada para crianças e adolescentes tal como foi inicialmente formulado (cf. Alvarez, 1996; Feld, 1997; Platt, 1997; TréPanier, 1999; Bailleau; Cartuyvels, 2007). A peculiaridade do estatuto está na combinação desse dispositivo com os dispositivos legais que restringem o isolamento institucional. Desta forma, ainda que o

1 Esse processo de especialização da justiça juvenil que passa a prever medidas, procedimentos e instituições específicos para adolescentes que cometeram crimes, é destacado também por autores que analisam as transformações recentes na justiça juvenil em países da Europa e da América do Norte (Cf. Trépanier, 1999; Bailleau, 2002; Piñero, 2006). 
tempo de internação permaneça sendo determinado por avaliações do adolescente e do processo desenvolvido ao longo da medida, a gravidade da infração assume relevância na aplicação da institucionalização, o limite máximo de internação é significativamente reduzido e a frequência das reavaliações é maior²

Considerando esse cenário, torna-se interessante investigar de que maneira o enquadramento legal peculiar estabelecido pelo estatuto é traduzido nas práticas dos atores que realizam cotidianamente a institucionalização de adolescentes. $\mathrm{O}$ dispositivo das sentenças indeterminadas adotado pelo ECA estabelece que o processo da execução será orientado pela necessidade de produzir a decisão sobre o encerramento da medida. Há, nesse dispositivo, o pressuposto de que, ao longo da medida, a situação inicial do adolescente será alterada e que a avaliação dessa alteração deve fundamentar a decisão sobre o término da intervenção. Permanecendo no plano da interpretação dos modelos estabelecidos pelas legislações, é possível dizer que a diferença de perspectiva do ECA com relação aos códigos de menores altera também o processo da execução das medidas. A relevância e o significado da decisão sobre o encerramento ou manutenção da internação é muito diferente dependendo dessa medida ser tida como meio de proteção e recuperação (ou seja, como medida desejável para o adolescente) ou como privação de um direito fundamental. Além disso, o aumento na frequência das reavaliações pode fazer com que o trabalho de produzir essas decisões e as evidências de transformação que as sustentam assuma centralidade na rotina institucional.

Desta forma, na interpretação proposta sobre o estatuto, a construção da decisão sobre o término da intervenção emerge como dimensão central do processo de execução da medida. Tendo em vista essa centralidade, o objetivo deste artigo é analisar o processo de produção da decisão sobre o encerramento da medida a partir dos resultados de uma pesquisa empírica realizada nas instituições responsáveis pela execução da medida de internação em São Paulo - Fórum Brás e Fundação CASA. Para tanto, a análise se concentra em um instrumento central

2 No caso do Código de Menores de 1979 (BRASIL, 1979), não havia limite máximo para a medida de internação e as reavaliações deveriam ser realizadas a cada dois anos (Art. 41, $\S 1^{0}$ ). Já no caso do Código de Menores de 1927 (BrAsıL, 1927), a definição do tempo de internação variava de acordo com as características do menor e do tipo de instituição: menores abandonados ou em situação de "vadiagem", "mendicidade", "libertinagem" poderiam ser internados até a maioridade; já para os menores delinquentes o tempo de internação previsto dependia do caso, os menores de 14 anos só poderiam ser internados em "casa de educação" ou "escolas de preservação" e a medida deveria durar "o tempo necessário à sua educação comtando que não ultrapasse a idade de 21 annos" (BRASIL, 1927, Art. 68, § $2^{\circ}$ ); no caso dos maiores de 14 anos, o tempo de internação nas escolas de reforma dependia deles serem "abandonados, pervertidos ou em perigo de o ser": em caso negativo, poderiam ser internados pelo período entre 1 e 5 anos, em caso positivo, pelo período de 3 a 7 anos. 
desse processo: os relatórios produzidos nas unidades de internação sobre os adolescentes. É esse instrumento que fundamenta - necessariamente, mas não exclusivamente - as reavaliações judiciais da medida previstas pelo estatuto. No caso da pesquisa realizada no Fórum Brás, os casos de internação são reavaliados a cada três meses ${ }^{3}$ pelos juízes do Departamento de Execuções da Infância e Juventude (DEIJ) ${ }^{4}$ sempre a partir dos relatórios formulados pelas equipes técnicas das unidades de internação da Fundação CASA - que podem ou não conter a sugestão de encerramento da medida. Ainda que os juízes do DEIJ possuam outros recursos para fundamentar sua decisão ${ }^{5}$, as discordâncias com a sugestão dos relatórios da Fundação CASA são raras e a grande maioria dos casos é decidida somente pelos relatórios.

O contexto específico da pesquisa reforça, assim, o papel decisivo que os relatórios desempenham no processo de produção da decisão sobre o término da medida de internação. Nesse sentido, para compreender como essas decisões são construídas, a análise dos relatórios torna-se fundamental. Na pesquisa, o acesso a esse material se deu pela consulta ao acervo institucional da Fundação CASA, onde estão arquivados os prontuários de todos os adolescentes que passaram pela instituição ${ }^{6}$. Esses prontuários contêm os documentos produzidos ao longo da trajetória institucional do adolescente e contemplam todas as suas passagens por unidades da Fundação CASA. Na maior parte dos casos, os prontuários contêm três tipos de relatório: relatório inicial (geralmente elaborado na unidade de internação provisória e, portanto, antes da sentença), relatórios de acompanhamento (produzidos nas unidades de internação e sua quantidade varia de acordo com o tempo

3 Conforme já indicado, o ECA estabelece que a medida de internação seja reavaliada a cada, no máximo, seis meses (Art. 121, $\S 2^{\circ}$ ). A determinação de que as reavaliações ocorram a cada três meses foi estabelecida pela Ordem de Serviço No 5/1999 do DEIJ.

4 Trata-se de um departamento do Fórum composto por quatro juízes exclusivamente dedicados ao acompanhamento da execução das medidas socioeducativas na capital. De acordo com Christiane Whitaker (2010), o estado de São Paulo é o único que possui um departamento com juízes exclusivamente dedicados a execução de medidas socioeducativas.

5 Para fundamentar sua decisão sobre o término ou manutenção da internação, os juízes podem ainda solicitar uma avaliação do caso pela Equipe Técnica do Juízo (ETJ) - composta por sete psicólogas e seis assistentes sociais que respondem às demandas dos juízes - ou marcar uma audiência com a equipe da Fundação CASA, o adolescente e sua família.

$6 \mathrm{O}$ acesso às pastas e prontuários foi possibilitado como desdobramento da pesquisa "Adolescentes em conflito com a lei: pastas e prontuários do "Complexo do Tatuapé (São Paulo/ $S P, 1990-2006$ )" submetida e aprovada pelo edital MCT/CNPq 03/2008, coordenada por Marcos Alvarez e executada no Núcleo de Estudos da Violência da Universidade de São Paulo. A partir do universo de 115.639 prontuários arquivados no período de 1990 a 2006, foi realizada uma pesquisa quantitativa de uma amostra probabilística de 1.581 prontuários. As análises dos resultados da pesquisa quantitativa podem ser verificadas nas seguintes publicações: ALVAREz et al., 2009; Alvarez et. al., 2010; Oliveira et al, 2014; Alvarez; Oliveira, 2015; e Oliveira, 2016. 
de internação) e relatório conclusivo (em que consta a sugestão de encerramento da medida). Ao todo, foram analisados 59 relatórios contidos em 9 prontuários7.

Cabe destacar que a análise que se pretende realizar desses documentos envolve uma abordagem particular. Os relatórios não serão tratados aqui como relatos objetivos que permitem acessar as atividades institucionais ou as características dos adolescentes. Conforme destaca Aaron Cicourel (1968, p. 27), o uso de documentos e estatísticas oficiais como informações objetivas ignora o trabalho interpretativo dos atores responsáveis pela produção dessas informações e o emprego de categorias e teorias de senso comum para produzir relatos coerentes "do que aconteceu". O problema em ignorar esse trabalho interpretativo é que o pesquisador acabaria produzindo teorias e explicações que subscrevem às tipificações nativas utilizadas na produção dos documentos institucionais. Como alternativa, o autor (1968, p. 27) propõe que o foco seja direcionado para a compreensão de como um conjunto de informações vagas e desconectadas são sucessivamente transformadas em um acontecimento ordenado.

O que Cicourel destaca, assim, é que algo é produzido no ato de relatar e que é precisamente essa dimensão produtiva da construção dos relatos que deve ser objeto de investigação. Consoante com a abordagem etnometodológica, o autor rejeita a possibilidade de considerar os documentos como independentes dos contextos e dos usos organizacionais de sua produção e interpretação (cf. GARFINKEL, 1967; Sмiтн, 1993). Nessa chave, a objetividade, a racionalidade e facticidade não são concebidos como atributos intrínsecos aos documentos institucionais, mas como realizações práticas dos atores que os produzem e utilizam (Cf. ZIMMERMAN, 1974; Sмiтн, 1993). O que interessa na análise dos documentos é compreender, assim, o processo de objetivação ${ }^{8}$ das ações e decisões institucionais.

Seguindo essa abordagem, os relatórios das unidades de internação serão considerados a partir do contexto prático de sua elaboração, como parte das atividades rotineiras dessas organizações. O interesse em inserir a construção dos relatos oficiais no contexto dos problemas e preocupações práticos dos membros das organizações investigadas está na possibilidade de considerar os documentos

7 A seleção dos prontuários partiu de uma pré-seleção realizada pelos pesquisadores que coletaram os dados quantitativos e da descrição que eles formularam de cada prontuário selecionado para análise qualitativa.

8 Em discussão sobre a forma como a sociologia constrói a objetividade dos dados que utiliza, Cicourel propõe esse termo para designar a tentativa do observador ou do ator de convencer seu interlocutor da credibilidade das propriedades e elementos do que se chama de "dados" ou "fatos" com a finalidade de fazer inferências para ações futuras. Assim, "objetivar" um evento ou objeto seria convencer alguém de que fundamentos suficientes existem para fazer inferências sobre "o que aconteceu". 
produzidos como relatos motivados (motivated accounts) dos atores e não como "fatos" da estrutura formal das organizações (RAWLS, 2003, p. 218). Como não foi possível acompanhar as atividades de produção e recepção dos relatórios e observar os procedimentos empregados pelos atores para transformar as ocorrências da unidade em relatos escritos, o contexto prático dos relatórios foi elaborado a partir das informações obtidas nas conversas e entrevistas com os atores responsáveis por elaborá-los e processá-los 9 . Considerando que as entrevistas e a consulta aos prontuários foram realizadas em etapas distintas da pesquisa ${ }^{10}$, as informações usadas para reconstituir o contexto prático operam como esquema interpretativo para análise dos documentos propriamente ditos.

Assim, como alternativa ao tipo de análise que olha somente através dos documentos, busca-se olhar para eles, buscando restaurar analiticamente sua visibilidade como mediadores produtivos (Hull, 2012, p. 253). A proposta consiste em realizar uma leitura dos documentos menos centrada no conteúdo discursivo ou representacional que exibem - se distanciando, em parte, da forma como os documentos têm sido usualmente tratados nas análises sobre a institucionalização e o processamento judicial de adolescentes ${ }^{11}$ - e mais interessada nos procedimentos empregados na produção desses relatos. Essa abordagem segue a proposta de Dorothy Smith (1993, p. 38) na sua análise dos procedimentos adotados na construção de relatos sobre uma pessoa se tornando doente mental. De maneira semelhante, o objetivo com a análise dos relatórios das unidades é identificar os procedimentos empregados para produzir nos relatos a razoabilidade da decisão de liberar o adolescente da unidade.

A abordagem empregada na análise desse material pode ser aproximada também da desenvolvida por Kenneth Morrison (1981). Com o objetivo de tornar

9 Ao longo da pesquisa de campo, realizei entrevistas com os quatro juízes do DEIJ, cinco defensores públicos, seis profissionais da ETJ e vinte e oito funcionários de quatro unidades de internação da Fundação CASA.

10 A opção por tratar as entrevistas como esquema interpretativo para análise dos relatórios se deve também à diferença temporal entre os materiais: as entrevistas foram realizadas em 2013 e os prontuários analisados compreendem o período entre 1991 e 2010. O período a que cada prontuário (PT) se refere: PT(A) 1991-1993; PT(B) 1996-1997; PT(C) 1998-2000; PT(D) 1999-2000; PT(E) 2005-2008; PT(F) 2005-2010; PT(G) 2006-2009; PT(H) 2006-2008; PT(I) 2006-2010. Como os prontuários contêm todas as passagens dos adolescentes por unidades de internação, esse período não traduz o período de internação dos adolescentes, mas o intervalo entre o primeiro relatório da primeira internação e o último relatório da última internação.

11 Inúmeras pesquisas sobre a temática analisam os documentos a partir de análise do discurso ou das representações sociais. Para alguns exemplos de análise de pareceres e laudos psicológicos elaborados durante a execução de medidas socioeducativas, ver DinIZ, 2001; FrasSETO, 2005; Mosqueira, 2013. Para análises dos relatórios ou dos prontuários institucionais como um todo: RODRIGUES, 2001; LIMA, 2014. E para a análise de processos judiciais: CASTRO, 2006; ÁGUIDO et al, 2013; SARTÓRIO; Rosa, 2010. 
'objetos de conhecimento’ disponíveis para estudo sociológico, o autor busca analisar os tipos de estruturas dos formatos (designs) exibidos em materiais pedagógicos. Morrison propõe analisar esses materiais com foco na dimensão organizacional de seus formatos. O objetivo é buscar os atributos recorrentes da organização sequencial que os materiais exibem para demonstrar de que maneira a estrutura do formato é produtiva dos eventos pretendidos no texto (como, por exemplo, "fatos", "evidências" e "respostas corretas").

Retomando o tema de interesse do presente artigo, é possível dizer que o evento pretendido nos relatórios das unidades é a decisão de liberar ou não o adolescente. Nesse sentido, os padrões nos procedimentos empregados nos relatos foram formulados a partir da identificação da organização dos formatos que eles exibem. Ao invés de organizar os relatórios pelos casos a que se referem - analisando todos os relatórios produzidos sobre o mesmo adolescente -, optou-se por distribuí-los a partir dos tipos de relatórios mais recorrentes nos prontuários: relatório inicial, relatório de acompanhamento e relatório conclusivo. A comparação dos relatórios de um mesmo tipo visou verificar em que medida há padrões na forma como eles são construídos.

\section{O CONTEXTO PRÁTICO DOS RELATOS}

Considerando que se pretende compreender os documentos institucionais como relatos motivados (RAWLS, 2003, p. 218), cabe destacar que os relatórios das unidades de internação não são documentos exclusivamente "internos" direcionados principalmente aos demais membros da unidade. Os relatórios têm como propósito principal orientar a decisão judicial sobre a manutenção ou término da internação. Eles são, assim, um tipo de relato produzido "para fora" da instituição, que será utilizado por atores que não presenciaram as situações e interações descritas no relatório para produzir suas decisões ${ }^{12}$. Conforme detalhado anteriormente, na grande maioria dos casos, a decisão dos juízes do DEIJ é feita exclusivamente pela consulta aos relatórios. É possível supor, assim, que o trabalho envolvido na produção dos relatórios envolve elaborar descrições convincentes do que aconteceu para justificar as ações da equipe e a decisão de sugerir

12 Afirmar que os relatórios são relatos produzidos "para fora" da instituição não significa que eles não sejam mobilizados nas relações no interior das unidades de internação. Ao longo da pesquisa foi possível observar que os relatórios são um importante instrumento para a manutenção da ordem interna da unidade, sendo utilizados pelos funcionários para negociar o comportamento dos adolescentes. Essa dimensão não será abordada neste artigo por ensejar uma discussão própria. Cabe indicar, no entanto, que essa dinâmica do funcionamento das unidades e a forma como o poder do registro é utilizado nas relações, permite refletir sobre os documentos a partir de seu status como artefato (cf. Rilles, 2006). 
ou não a liberação do adolescente. Como apontado anteriormente, Cicourel (1968) argumenta que a produção de relatos escritos e orais é decisiva no processo de objetivar os eventos e objetos envolvidos na produção do delinquente ao longo das diferentes etapas do sistema de justiça juvenil. De maneira semelhante, a construção dos relatórios envolve o trabalho de convencer os atores do Fórum de que há fundamentos suficientes e válidos para fazer inferências sobre "o que aconteceu" e decidir sobre a liberação do adolescente.

A necessidade de construir nos relatórios a razoabilidade das ações e decisões da equipe técnica tornando-as reconhecíveis e, portanto, justificáveis, é reforçada pelo contexto específico que informa a relação entre os juízes do DEIJ e a Fundação CASA. Os juízes elaboram a avaliação e a fiscalização do trabalho realizado nas unidades como parte de suas atribuições, e consideram esse trabalho fator decisivo dos efeitos da medida. Para eles, os efeitos da medida dependem muito da qualidade do trabalho das equipes, o que varia entre as diferentes unidades. Além disso, há entre os juízes uma desconfiança de que o envio de relatórios conclusivos seja motivado pela necessidade da Fundação CASA de liberar vagas. O principal parâmetro adotado pelos juízes para controlar a "coerência" e adequação dos relatórios é a gravidade do ato infracional.

Nas entrevistas realizadas com os diferentes profissionais que participam do processo de elaboração dos relatórios, essa atividade era frequentemente apresentada como um problema prático e "burocrático". Nas falas, a necessidade de produzir os relatórios em pouco tempo figurava entre as demandas excessivas de trabalho. De acordo com eles, a grande quantidade de adolescentes por profissional (em torno de 20 no caso de psicólogas e assistentes sociais) somada a frequência dos relatórios deixariam os profissionais sobrecarregados e impactaria a qualidade do trabalho. Essa preocupação com a "qualidade do relatório" era vinculada, por sua vez, às cobranças do judiciário e ao risco de ter o relatório questionado ou negado pelo juiz. No relato dos funcionários, o trabalho realizado para evitar que essa possibilidade se concretize envolveria a produção de um relato coerente em que não há discordâncias, contradições ou "brechas":

E o judiciário é bem rigoroso (...) Se a gente não manda [o relatório] eles cobram, né? Eles oficiam, se você não manda, vem o oficial de justiça aqui na unidade pra cobrar (...) Mas embasado naquela discussão, né? Senão vai cada pessoa falar uma coisa, né? Então tem que ser embasado na discussão, porque pra essas pessoas que tem uma opinião diferente, tem que se chegar a uma conclusão (...) Né? Então tem que tá de acordo, os pareceres, às vezes a segurança fala "ah, o menino dá problema na sala de aula", aí a pedagogia fala: "Não, ele 
não dá problema na sala de aula", então não existe, né, isso, então tem que ter uma conversa. (Psicóloga 2, Encarregada Técnica - Unidade 3)

Particularmente, quando você vai fechar um caso, subentende-se que você tem que ter, a equipe tem que estar coesa (...) Então, assim, o juiz olha, se cada um falar na mesma linhagem, né, digamos assim, ele entende que (risos) tá tudo relativamente ordenado. (...) "Ah, vamos fazer de tal menino?" "Vamos", aí tem divergências, discute um pouco o caso, cada um se posiciona, mas pra fazer e se fechar, esse todo aqui tem que estar bem razoável, né, o conteúdo descrito, bem mais coeso, pra quem olhar e falar "opa, essa equipe fez um trabalho" (...) Então, se o promotor pega e olha, aí bate aqui na conclusão, né? (...) Então, assim, quando, é de novo que eu tô falando no conteúdo de relatório, quando o relatório vai e deixa brecha pra dúvida, o que o juiz fazia em São Paulo? Mandava a equipe dele chamar a família e o menino, pra conversar uma única vez. (Assistente Social 1 - Unidade 1)

Há, assim, a percepção da necessidade de sustentar, no relatório, a impressão sobre o trabalho realizado na unidade. O relatório não é visto exclusivamente como apresentação de informações sobre o adolescente, mas, também, como apresentação da própria instituição. A “coesão" e a "coerência” produzidas no relato são referidas ao trabalho da equipe e não ao adolescente. Nesse sentido, é possível compreender a atividade de produção dos relatórios como um exemplo de "performance de equipe" que envolve o manejo das impressões relativas à "fachada" institucional (GoFFman, 1990).

Tendo esse cenário em vista, é possível supor que a construção da racionalidade da sugestão de liberação do adolescente ou manutenção da medida passa pela produção de evidências do trabalho desenvolvido pelos funcionários. Essa ideia é ainda reforçada pela discussão sobre o que a indeterminação do tempo de duração da internação pressupõe. A noção de que o término da institucionalização deve ser determinado pela avaliação da alteração ou transformação produzida na situação do adolescente significa que, para justificar a decisão de liberar o adolescente, os funcionários precisam produzir evidências dessa transformação como resultado do seu trabalho.

\section{OS RELATÓRIOS}

\section{RELATÓRIO INICIAL}

Os relatórios iniciais são compostos principalmente por dois tipos de informação: características e trajetória do adolescente e de sua família e evidências das 
causas que levaram o adolescente a cometer a infração. Cabe destacar ainda que é comum haver semelhanças entre os relatórios iniciais das diferentes passagens do mesmo adolescente. Na grande maioria dos casos, a descrição da trajetória do adolescente é somente atualizada e a situação que explica a infração é reapresentada. Essa relação entre os diferentes relatórios iniciais pode ser um indicativo de que a definição da situação do adolescente construída no primeiro relatório é utilizada para interpretar os novos atos infracionais.

Todos os relatórios iniciais analisados contêm alguma caracterização do adolescente e de sua família, indicando ser este um item necessário desse tipo de relatório. As informações específicas que são incluídas, no entanto, variam nos diferentes casos. É frequente a inclusão de características que indicam "problemas" na vida e trajetória do adolescente e que, em muitos casos, são apresentados como fatores que contribuíram para o adolescente cometer a infração. É o que se pode observar nos exemplos a seguir:

A genitora compareceu para entrevista e relatou-nos que conviveu maritalmente com o Sr. [nome do pai] ${ }^{13}$ durante 18 anos. Entretanto, o relacionamento foi conflituoso, pois desde o início ele mostrou ser extremamente ciumento e agressivo e fazia uso abusivo de etílicos. (...)

O Sr. [nome do pai] levava uma vida muito desregrada e quando [adolescente em questão] contava com o6 meses de vida, o pai foi baleado. Estilhaços de bala ficaram alojados em seu organismo e aos poucos teve sua saúde fragilizada. (...)

Há 04 anos o genitor faleceu em decorrência de complicações geradas por câncer no baço.

Com a morte do pai, os dois filhos mais velhos, [nome do irmão mais velho e do adolescente em questão], ficavam sozinhos e passaram a não acatar as orientações maternas.

A genitora, para conseguir atendê-los, pediu demissão do emprego, no entanto, o filho mais velho, [nome do irmão mais velho], já havia iniciado o uso de bebidas alcoólicas e envolver-se com más companhias, levando consigo o irmão [nome do adolescente em questão].

Para afastar os filhos do ambiente o qual estavam inseridos, a Sra. [nome da mãe] vendeu a casa e adquiriu outra no [nome do bairro], mas pouco adiantou,

13 Para garantir o anonimato dos adolescentes e de sua família, optei por omitir todos os nomes de pessoas ou lugares. 
pois, segundo a mãe, [nome do irmão mais velho], continua bebendo e exerce sobre o irmão influência negativa. (...)

O relacionamento familiar é descrito pelo jovem e genitora como tranquilo, exceto pelos problemas causados pelo mais velho.

Sobre o ato delitivo, o adolescente nega envolvimento, afirmando que, juntamente com o irmão, entrou no bar para tomar água e não viu se o mesmo realmente fez anúncio de assalto.

(Prontuário G - Relatório Inicial de 03/o7/06)

No contato informou-nos a genitora que o filho estava bem no lar, no início de sua desinternação, porém observou que [nome do adolescente em questão] havia retomado o contato com as amizades de influência negativa. Procurou conversar, orientar, no entanto, percebia pouca disposição da parte do filho em obedecer às suas recomendações. (...)

A Sra. [nome da mãe] relata que se encontra convivendo maritalmente com o Sr. [nome do padrasto] há cerca de 10 anos e possui duas filhas desta união ([nome das duas filhas]). Possui outros três filhos de relacionamentos anteriores breves, dos quais dois sumiram ao receberem a notícia da gravidez sem saber o paradeiro dos mesmos. (...)

Questionado sobre o uso de drogas alega fazer uso de maconha desde os 13 anos, tendo também experimentado cocaína, crack, cola, tinner, lança perfume e êxtase, tendo iniciado seu uso por curiosidade, nunca fez tratamento de drogadição e não se considera viciado, sendo conveniente que receba tratamento para tanto.

Afirma que já vem mantendo contato com amizades inadequadas desde os seus 12 anos de idade, tendo conhecido as mesmas no bairro. [Nome do adolescente em questão] conta com o3 passagens por esta Fundação por roubo de celular, sendo a entrada atual também por roubo de celular. (...)

$O$ relacionamento familiar segundo o jovem é descrito como harmonioso podendo contar com o apoio e respaldo de sua genitora, que segundo ele se mostra disponível a auxilia-lo quando da sua volta ao meio social. Notamos pelos relatos do jovem e pelos dados da leitura das peças que sua genitora não tem conseguido se impor como figura de autoridade frente aos filhos, pois tem um outro filho [nome de outro filho] também nesta fundação por motivo de roubo, sendo necessário que receba ajuda para tanto.

Tal falta de controle aliado à sua imaturidade e impulsividade, foram fatores que propiciaram para [nome do adolescente em questão] o contato com 
amizades inadequadas, com as quais iniciou no uso de drogas e no meio delitivo, e se sentindo acolhido no grupo passou a agir como os demais praticando atos delitivos sem medir as consequências dos mesmos, e como estava iludido pelos ganhos fáceis desta vida não dava atenção aos conselhos de seus familiares.

(Prontuário F - Relatório Inicial de 14/04/2009)

Como é possível observar nos trechos reproduzidos, ainda que nem todas as características apresentadas do adolescente e de sua família sejam vinculadas causalmente ao ato infracional, em todos os relatórios iniciais há o esforço de construir uma explicação para a infração, a partir dessas informações. Dado a necessidade de extrair dessa apresentação uma explicação para o delito, elaboram-se os elementos "suficientes" para a construção das causas. A forma como um atributo específico assumirá relevância explicativa no relato varia nos diferentes prontuários: enquanto no relatório do Prontuário G, o comportamento do irmão do adolescente é apresentado como fonte de "influência negativa" e é diretamente vinculado à infração; no caso do Prontuário F, o comportamento do irmão é utilizado como evidência da incapacidade da mãe de "se impor como figura de autoridade", o que, por sua vez, "propiciou" o contato com "amizades inadequadas" e com o "meio delitivo". A explicação específica produzida sobre o ato depende, assim, de uma organização interna a cada relatório, daí a variação nas características incluídas nos diferentes relatórios.

\section{RELATÓRIO DE ACOMPANHAMENTO}

Se os relatórios iniciais são majoritariamente dedicados a construir as características do adolescente e de sua família e produzir uma explicação para $\mathrm{o}$ ato infracional, nos relatórios de acompanhamento o foco é direcionado para as atividades e intervenções realizadas pela equipe e para o comportamento do adolescente na unidade. A maior parte das informações inseridas nesses relatórios são vinculadas a evidências do trabalho desenvolvido com o adolescente de modo a elaborar a razoabilidade das ações institucionais. Nesse sentido, esses relatórios são os que exibem mais claramente a atividade de accountability institucional, como relato produzido "para fora" da unidade.

Ainda que o foco desse tipo de relatório seja o contexto institucional e o que ocorre na unidade, em muitos relatórios de acompanhamento as características da família e da trajetória do adolescente são reapresentadas, mas agora vinculando-as às medidas adotadas pela equipe: seja como resultado delas (no caso das visitas domiciliares) ou como o que as motivou: 
Aos 22/06/07, realizamos visita domiciliar, quando confirmamos a fala do jovem de que seus pais estão separados, mas que residem muito próximos (são vizinhos).

Ao chegarmos na residência, quem nos recebeu foi Sra. [nome da mãe], 39 anos, que, de pronto nos pareceu uma pessoa com saúde física e mental debilitada, embora não formulasse queixas, apenas apresentando um discurso repetitivo de que não é louca. Inicialmente negou, mas diante da afirmação da filha [nome da irmã], 12 anos, assumiu que já passou por avaliação psiquiátrica, não querendo falar sobre o assunto.

A Sra. [nome da mãe] mostra-se devitalizada (sic) e descrente em relação à vida. Pareceu-nos ainda, uma pessoa alheia à realidade interna e externa, que necessita com urgência de ajuda - atendimento médico/psicoterápico. (...)

Diante dessa problemática, encaminhamos a Sra. [nome da mãe], para tratamento médico/psiquiátrico na UBS do bairro [nome do bairro], assim como o Sr. [nome do pai] e a filha [nome da irmã], uma vez que, a adolescente é quem cuida da mãe, e assume as responsabilidades quanto aos afazeres domésticos, o que, de certa forma, acaba lhe trazendo uma sobrecarga muito grande.

Além do encaminhamento para Acompanhamento Psicológico e de Orientação Familiar, na oportunidade oferecemos verba para ajuda de custo para transporte, e a Sra. [nome da mãe] e [nome da irmã] têm vindo visitar [nome do adolescente em questão], o que lhe trouxe grande contentamento, e tem nos possibilitado trabalhar o sentimento de pertinência familiar.

(Prontuário H - Relatório de acompanhamento de 16/07/2007)

Além dessa construção das medidas adotadas a partir da caracterização da situação familiar, um dos principais meios através dos quais se produz a razoabilidade das ações e intervenções da equipe consiste na descrição das atividades nas quais o adolescente foi inserido na unidade a partir das transformações que elas podem gerar em seu comportamento:

Quanto às oficinas artesanais desenvolvidas na unidade pelos funcionários do setor pedagógico, as quais tem por objetivo desenvolver e aprimorar a coordenação motora, concentração, sociabilização e cooperação participou das oficinas de confecção de bonecas de lã e decoupage. Durante estas atividades demonstrou destreza e interesse em todas as oficinas. (...)

Frequenta a oficina temática de drogadição, feita pelos funcionários do setor pedagógico, com o objetivo de que o adolescente seja capaz de se identificar como 
responsável pelas suas escolhas; sendo assim capaz de evitar problemas futuros com a conscientização dos malefícios do tráfico de drogas dentro da sociedade.

Participa de curso profissionalizante de arbitragem organizado pela [nome da associação de arbitragem], o qual tem por objetivo formar juízes de futebol competentes e acima de tudo incentivar ojogo limpo e lograr uma interpretação uniforme e correta das regras do jogo, a fim de evitar mal-entendidos, lesões e situações controvertidas. É interessante ressaltar que o próprio adolescente pediu para ser inserido no curso e que até o presente momento tem apresentado um bom rendimento. (...)

Está inscrito e participando do curso profissionalizante de criatividade regulamentado pela “[nome da organização]” e ministrado por um corpo pedagógico capacitado para tal. Essa atividade tem como propósito incentivar sua capacidade de criar, de dar origem, formar e gerar para desenvolver competências, para uma atuação voltada à quebra de paradigmas que bloqueiam o processo de criação além de melhoria contínua, desativando o condicionador de hábitos das pessoas.

(Prontuário I - Relatório de acompanhamento de 22/04/2008)

Como é possível observar nesse exemplo, as atividades ofertadas nas unidades são apresentadas nos relatórios de acompanhamento a partir de seus "objetivos" e "propósitos" elaborados pelos efeitos que podem promover no adolescente (inserção no mercado de trabalho, conscientização, aquisição de certa atitude). As atividades pedagógicas, culturais e profissionais são formuladas, assim, como meio de intervir no comportamento do adolescente. Esse procedimento narrativo permite apresentar a rotina institucional como intencionalmente planejada para operar uma transformação no adolescente.

Paralelamente a essa construção da coerência do trabalho desenvolvido na unidade, como se pode ver nos trechos reproduzidos, a descrição das atividades é também acompanhada de avaliações do desempenho e comportamento do adolescente ao executá-las. Nessa avaliação, não há distinção entre a disposição e interesse do adolescente na realização das atividades pedagógicas, culturais e profissionais e as "faltas disciplinares" ou obediência às normas e regras da unidade. Qualquer comportamento do adolescente pode ser avaliado, vinculado às intervenções realizadas e construído como evidência de sua transformação.

Observamos que neste período de 40 dias o jovem mostrou-se com dificuldades de adaptação pois sempre manifesta 'queixas' na área de atendimento médico e odontologista como forma de chamar atenção, talvez por apresentar 
carência afetiva, mas que após intervenção técnica apresenta boa adaptação às normas de atendimento, com receptividade as nossas orientações.

(Prontuário D - Relatório de acompanhamento de 27/01/2000)

Em relação ao jovem [nome do adolescente em questão], enquanto interno, vem apresentando oscilações em seu comportamento com atitudes impulsivas envolvendo-se em episódios indisciplinar (sic). Em virtude destas condutas culminou em vários boletins de ocorrência, nesta unidade. (...)

No momento constatamos que [nome do adolescente em questão], apresenta-se em processo de elaboração crítica, onde nos atendimentos psicossociais tem sido levado a refletir quanto sua situação pregressa. O jovem tem vivenciado período onde busca reavaliar sua conduta e valores e para tal solicita auxílio desta equipe técnica, principalmente em momentos de maior instabilidade emocional e angústia.

Ojovem apresenta até então dificuldade em controlar sua impulsividade o que acaba por refletir em atitudes permeadas de agressividade, uma vez que, de forma defensiva, por vezes, 'atacando', conforme informado a esse juízo de acordo com avaliações da Comissão de Avaliação disciplinar desta UI. Compreendemos que, tal dinâmica, esteja relacionada a seu desenvolvimento (sic).

(Prontuário I - Relatório de acompanhamento de 23/10/2009)

Para finalizar a análise dos relatórios de acompanhamento, cabe destacar que não consta nesses relatórios a sugestão de manutenção da medida. Diferente dos relatórios conclusivos - cuja análise desenvolverei a seguir -, as informações não parecem ser inseridas em função de uma sugestão final, como elaboração de sua razoabilidade. Quando existe, na "conclusão" dos relatórios geralmente consta somente a afirmação de que a equipe dará continuidade ao trabalho. Outro indicativo de que o relatório de acompanhamento não é organizado pela construção da decisão de manutenção da medida é a variação na avaliação do adolescente. Ainda que os relatórios de acompanhamento sejam repletos de avaliações do adolescente, elas podem ser tanto majoritariamente negativas quanto majoritariamente positivas. No caso do prontuário $\mathrm{H}$, por exemplo, em uma das passagens em que o adolescente permanece 2 anos e 4 meses internado, constam cinco relatórios de acompanhamento sendo que em quatro deles a avaliação do adolescente é positiva. Somente no último relatório de acompanhamento menciona-se a decisão de manter o adolescente internado e a sua motivação: o adolescente teria se envolvido em 
um "tumulto" na unidade e, por isso, a equipe reviu a decisão de enviar o relatório conclusivo para o juiz.

Ainda que seja frequente nos relatórios de acompanhamento a presença de avaliações dos comportamentos e atitudes do adolescente na unidade, não há a construção de uma decisão a partir dessa elaboração de evidências de transformação. Como não há uma decisão sendo formulada, não se extrai consequências das avaliações e sua inclusão fica submetida à construção do trabalho desenvolvido na unidade cuja demonstração é o foco principal desse tipo de relatório.

\section{RELATÓRIO CONCLUSIVO}

Busquei desenvolver ao longo deste item o argumento de que os relatórios iniciais e os relatórios de acompanhamento exibem construções típicas que permitem, por sua vez, elaborar seus focos principais de atenção: produção da explicação para a infração e demonstração das evidências do trabalho desenvolvido na unidade, respectivamente. Como visto, no entanto, há variações no tipo de informação e na forma específica como as informações são inseridas nesses relatos (por exemplo, as avaliações do adolescente nos relatórios de acompanhamento). Além disso, nem todos os prontuários analisados contêm esses tipos de relatório. Essa variação não existe no caso dos relatórios conclusivos: eles estão presentes em todos os prontuários e para todas as passagens dos adolescentes por unidades de internação. Esse tipo de relatório é também o que exibe maior homogeneidade no que diz respeito à sua organização e eles são sempre significativamente mais extensos que os relatórios iniciais e que os de acompanhamento. A análise comparada dos tipos de relatório pode ser usada para interpretar essa característica como indicativo de que há uma preocupação maior com a elaboração e registro dos relatórios conclusivos.

Uma das principais características que compõem a homogeneidade desse tipo de relatório é a centralidade assumida pela sugestão de liberação do adolescente na organização do relato. Conforme destacado, diferente dos relatórios de acompanhamento, todos os relatórios conclusivos contêm a sugestão de encerramento da internação. Nesses relatos, as avaliações sobre o comportamento e atitude do adolescente e sobre sua situação familiar são sempre majoritariamente positivas, sugerindo que as informações são inseridas em função da sugestão final, como elaboração da razoabilidade da decisão de liberar o adolescente.

O jovem foi devidamente orientado sobre a importância e a necessidade de refletir e rever sobre sua proposta social (escola, trabalho e família). 
[Nome do adolescente em questão] não denota vivência infracional e, no momento, apresenta-se receptivo às nossas orientações, tendo um desempenho educacional satisfatório.

A genitora pede pela desinternação do jovem, afirma que irá auxiliá-lo em sua reintegração social 'sic'. Pretende no futuro fixar residência em outra cidade. Acredita que seu filho está sendo prejudicado por conviver nesta cidade grande e com tantos problemas sociais. (...)

Através de entrevista coletada com o jovem e com a sua genitora respectivamente, pudemos constatar que [nome do adolescente em questão] provém de uma família organizada e harmoniosa no qual o relacionamento é satisfatório entre todos os seus integrantes. A mãe nos pareceu pessoa bastante adequada; transmitindo muito afeto e preocupação com a situação atual de seu filho. (...)

Ojovem nos pareceu maduro e reflexivo sobre seus atos, transmitindo segurança e sinceridade em seu relato. Acredita que será boa a mudança de cidade para ele.

Não foi possível fazer um estudo mais aprofundado à nível de personalidade (sic) e; aparentemente não foi percebido nenhum comprometimento emocional no garoto e não sentimos no momento necessidade de fazer encaminhamento nessa área.

\section{CONCLUSÃO E SUGESTÃO}

Diante do acima exposto, somos favoráveis que o jovem seja desinternado para a sua família, tendo em vista que o mesmo conta com respaldo familiar satisfatório e por acreditarmos no seu próprio potencial de pessoa em desenvolvimento.

(Prontuário A - Relatório conclusivo de 20/06/1991)

Os relatórios conclusivos são, assim, os que exibem mais claramente o esforço de construção de um relato coerente. E essa característica parece estar relacionada ao fato desse ser o único tipo de relatório que contém claramente a construção de uma decisão.

Conforme destacado, portanto, a centralidade da sugestão de liberação para a organização dos relatórios conclusivos pode ser percebida no caráter positivo das avaliações feitas do adolescente e de sua família. A construção da razoabilidade da decisão de liberar o adolescente pode envolver, no entanto, a inclusão de características negativas. É frequente que os relatórios conclusivos apresentem inicialmente os problemas no comportamento do adolescente e no contexto fami- 
liar para em seguida indicar as medidas adotadas com relação a essa situação e a mudança observada que, por sua vez, fundamenta a decisão final:

\section{Estudo social}

No início da internação [nome do adolescente em questão] apresentava-se para entrevista neste setor técnico colocando-se no lugar de vítima frente a causa que gerou a internação e insistia em passar a culpa para o outro, deixando transparecer em seu discurso uma certa resistência para repensar acerca de suas atitudes, bem como, de suas responsabilidades, como também demonstrando estruturação no meio infracional. (...)

Frente ao histórico sócio-familiar de [nome do adolescente em questão], procuramos levá-lo a exercer a capacidade de reflexão e gradativamente ele passou a admitir que fazer parte da população desta fundação CASA, está associada ao fato de se deixar levar pelos companheiros de conduta nefasta, sem considerar a educação dispensada pelos pais, mesmo eles insistindo para que procurasse seguir o caminho do bem. (...)

A Sra. [nome da mãe] informou ainda que está fazendo parte de um Grupo de Orientação e Apoio à Família, no [nome da instituição], na cidade de [nome da cidade], aguardando o retorno do filho ao lar e que acredita que está preparada e alertada para respalda-lo positivamente quando em liberdade, porém de maneira coerente com sua problemática até que ocorra efetivamente a reinserção na sociedade.

Diante da postura da mãe, o jovem começou a sensibilizar-se, manifestar interesse de assumir suas responsabilidades reconhecendo a dedicação dos pais e verbalizar que pretende de fato, estudar para seguir a carreira de aviador junto as Forças Aéreas Brasileira, ou cursar a faculdade de administração de Empresas, deixando transparecer uma melhora considerável em sua postura, verbalização e elaboração do projeto de vida.

\section{Estudo Psicológico}

(...) Revela-se um interno que consegue lidar e conviver adequadamente com as normas e regras e valores sociais vigentes.

É receptivo às orientações técnicas, prestativo e educado, o qual é orientado no tempo e no espaço, dispondo de recursos internos suficientes para sua reinserção na sociedade. 
Com o auxílio das intervenções que vem sendo submetido, o jovem conseguiu introjetar valores éticos mais adequados, além de elevação da autoestima e valorização dos relacionamentos sociais.

Procuramos no decorrer desse período levá-lo a refletir sobre os motivos que o levaram a distanciar-se do núcleo familiar e estreitar relação com a vida ilícita.

Referente ao conflito com a lei, percebe e não se isenta de sua responsabilidade, e reúne condições para estabelecer critica adequada, sobre suas experiências, inclusive se valendo desse aprendizado, no processo de amadurecimento a qual está atrelado a adequação a medida imposta. (...)

Portanto, pelo descrito acima, e avaliando que o jovem adulto denota ter adquirido crítica durante o processo de internação, e ainda entendo que conta com adequado respaldo familiar, sugerimos progressão de medida para [nome do adolescente em questão], visto encontrar-se apto a retornar a sociedade, em abrandamento de medida em Liberdade Assistida.

(Prontuário E - Relatório conclusivo de 03/06/2008)

Assim, a introdução de atributos problemáticos parece ser um recurso importante nesses relatos para a produção do fato da transformação do adolescente como resultado da ação institucional. A decisão de encerrar a internação é formulada não somente a partir da avaliação positiva das características do adolescente, mas do fato de que uma situação inicial foi alterada durante a medida e como resultado dela. A demonstração e produção de evidências do trabalho desenvolvido pela equipe - típica dos relatórios de acompanhamento - está também presente nos relatórios conclusivos, agora como fator decisivo da transformação operada no adolescente e na sua família. $\mathrm{E}$, seguindo o mesmo raciocínio exibido nos relatórios de acompanhamento, a transformação elaborada é quase exclusivamente de atributos individuais, como obediência às regras e reflexão sobre escolhas e ações pregressas.

\section{CONCLUSÃO}

Em sua pesquisa sobre a organização social da justiça juvenil, Aaron Cicourel (1968) busca sustentar o argumento de que a delinquência juvenil é um produto das agências de controle social. O autor (1968, p. 53) demonstra como no processo de tomada de decisão nos diferentes estágios do sistema de justiça juvenil, os atores usam expectativas de fundo para buscar explicações "válidas" "do que aconteceu" e justificar suas decisões. Ao longo desse processo, os objetos e eventos seriam progressivamente transformados de modo que as contingências, circunstâncias e 
teorização empregadas vão sendo alteradas, reificadas ou eliminadas. Partindo da percepção da existência de delinquentes como 'tipos sociais naturais', relatos orais e escritos sobre "o que aconteceu" são produzidos e reconhecidos como possuindo conteúdo factual de sentido ‘óbvio’. O delinquente seria o produto emergente desse processo que, como um boato, é progressivamente transformado nos diferentes relatos que se tornam cada vez mais concisos, consistentes e coerentes com as expectativas organizacionais (CiCOURIEL, 1968, p. 333).

É possível dizer que o processo de execução da medida de internação se inicia depois de encerrado o processo analisado por Cicourel; depois que se decidiu positivamente sobre a existência de delinquência e que o adolescente foi etiquetado como delinquente. O processamento rotineiro dos adolescentes, no entanto, permanece como problema prático depois que ele é inserido na instituição. Ao manter indeterminado o tempo de duração da internação, o enquadramento legal do ECA estabelece que ao longo da institucionalização é preciso produzir a decisão sobre o término da medida. Essa decisão precisa ser produzida não somente durante a execução da medida, mas como produto dela. Para ser justificável e razoável, a decisão de liberar o adolescente precisa estar vinculada às mudanças e alterações geradas pela medida. Na análise realizada sobre o contexto prático da produção e recepção dos relatórios, a necessidade de vincular a decisão aos efeitos da medida se expressa na preocupação dos funcionários com o caráter de accountability institucional dos relatórios. Esses relatos são concebidos pelos funcionários como instrumento de avaliação não só do adolescente, mas também do trabalho desenvolvido por eles. A atividade de escrever o relatório envolveria, assim, o trabalho de eliminar as possíveis discordâncias, inconsistências e "brechas" nas posições dos diferentes funcionários sobre o adolescente. A inscrição textual "do que aconteceu" na unidade passa pela construção de um relato coerente em que se elimina o caráter local, contingencial e processual dos eventos que informam a atividade de construir o relato (cf. GARFINKEL et al, 1981).

Considerando essa dimensão produtiva da atividade de elaboração dos relatórios, a análise realizada desses documentos buscou identificar os procedimentos empregados na construção da decisão de liberar o adolescente. Na análise, foi possível identificar que os três formatos de relatório existentes nos prontuários exibem organizações típicas que envolvem o emprego de procedimentos específicos e pretendem eventos distintos. No caso do relatório inicial, o evento pretendido é a explicação do ato infracional a ser extraída das caracterizações da família e do adolescente. A seleção de quais características serão apresentadas e o quanto elas serão detalhadas depende da organização interna a cada relato e de como a relação 
de causalidade é extraída dessa caracterização. Cabe destacar que a recorrência da presença de informações sobre a família e das condições de vida do adolescente parece ser indicativo de que o conteúdo das explicações formuladas exibe um atributo típico: a infração cometida pelo adolescente é frequentemente atribuída ao "meio" em que ele vive, seja a família, a vizinhança ou os amigos.

No caso dos relatórios de acompanhamento, o foco é deslocado do "meio" que explica a infração para o trabalho desenvolvido pela equipe e para o comportamento do adolescente na unidade. Nesses relatos, as informações são organizadas de modo a produzir evidências de que as atividades desenvolvidas na unidade foram intencionalmente pensadas para produzir transformações no adolescente. $\mathrm{O}$ desempenho e interesse do adolescente nas atividades, seu comportamento diante das regras institucionais ou sua atitude na relação com os outros adolescentes ou com a equipe são indistintamente avaliados e formulados como índices do processo de transformação. Outra característica da organização desse formato é a ausência da decisão de manutenção da medida. Conforme destacado, as avaliações apresentadas do adolescente podem ser tanto majoritariamente positivas quanto negativas, pois não há uma decisão sendo fundamentada.

Por fim, o relatório conclusivo é o único organizado explicitamente em função de uma decisão. Assim como os relatórios de acompanhamento, esses relatos também são repletos de avaliações do adolescente e de seu comportamento, mas aqui só há avaliações negativas para caracterizar uma situação inicial modificada pela ação institucional. Com frequência, a organização sequencial dos relatórios conclusivos envolve a construção de uma situação inicial problemática, seguida da descrição das atividades e medidas adotadas pela equipe para apresentar, por fim, a alteração produzida na situação inicial, formulada como consequência das medidas adotadas.

O que a análise dos procedimentos empregados nos diferentes tipos de relatórios sugere é que depois de construído o problema no relatório inicial, com recurso às informações sobre o passado e o contexto de vida do adolescente, no relatório de acompanhamento e no conclusivo, as informações são organizadas de modo a objetivar os efeitos da medida. Nesses relatos, a atenção passa a ser direcionada aos comportamentos e situações passíveis de mudança pela ação institucional. Por um lado, as informações sobre a família passam a se limitar ao que é avaliado positivamente e ao que pode ser (ou foi) "resolvido" pelas medidas adotadas pela equipe. Por outro, os comportamentos, atitudes e valores individuais do adolescente ganham destaque como evidências do processo de transformação. O trabalho desenvolvido na unidade também se torna alvo privilegiado de atenção nesses 
dois formatos, seja pela apresentação das intervenções como consequência das avaliações realizadas do adolescente, seja pela formulação das atividades a partir dos seus efeitos transformadores. Considerando que a indeterminação do tempo de duração da internação se assenta sobre o pressuposto de que são as alterações no indivíduo que devem fundamentar a decisão sobre o encerramento, os relatórios desempenham papel central no processo de execução das medidas socioeducativas. Em especial no caso do relatório conclusivo, no processo de elaborar a razoabilidade da decisão de liberar o adolescente, esses relatos participam da objetivação dos efeitos da medida. Se, no caso do estudo de Cicourel, o produto emergente do processo analisado é o delinquente, durante a execução o produto emergente é o fato da transformação do adolescente como efeito da medida, produto esse que depende de modo fundamental da construção dos relatórios.

\section{REFERÊNCIAS BIBLIOGRÁFICAS}

Águido, Cynthia Maria Santos; Cacham, Alessandra Sampaio; Fazzi, Rita Cássia. Representações sociais dos juízes da infância e juventude na aplicação da privação de liberdade a adolescentes autores de ato infracional. Dilemas: Revista de Estudos de Conflito e Controle Social, v. 6, n. 2, p. 295-330, Abr/Mai/Jun, 2013

Almeida, Bruna Gisi Martins de. O verdadeiro arrependimento como processo: o lugar da infração na execução da medida socioeducativa de internação. Confluências, Niterói, v. 16, p. 220-243, 2014.

Alvarez, Marcos César. A emergência do código de menores de 1927: uma análise do discursojurídico e institucional da assistência e proteção aos menores. Universidade de São Paulo. Faculdade de Filosofia, Letras e Ciências Humanas - Departamento de Sociologia. Dissertação (mestrado). São Paulo, 1989.

Bacharéis, criminologistas e juristas: saber jurídico e nova escola penal no Brasil (1889-1930). Universidade de São Paulo. Faculdade de Filosofia, Letras e Ciências Humanas. Departamento de Sociologia. Programa de Pós-Graduação em Sociologia. Tese (Doutorado). São Paulo, 1996.

Alvarez, Marcos César; Oliveira, Thiago Rodrigues. Pastas e prontuários do "Complexo do Tatuapé” (São Paulo/SP - 1990-2006): alterações nos padrões da justiça juvenil após o ECA. In: Anais do $39^{\circ}$ Encontro Anual da ANPOCS, 2015.

Alvarez, Marcos César; SAlla, Fernando; Schritzmeyer, Ana L. Adolescentes em conflito com a lei: pastas e prontuários do "Complexo do Tatuapé” (São Paulo/SP, 1990-2006). In: Anais do $7^{\circ}$ Encontro da ABCP, 2010.

Alvarez, Marcos César; Schritzmeyer, Ana L.; SAlla, Fernando; Paula, Liana; Cukierkorn, Mônica. Adolescentes em conflito com a lei: pastas e prontuários do "Complexo do 
Tatuapé" (São Paulo/ SP, 1990 - 2006). Rev. Bras. Adolescência e Conflitualidade, v. 1, n. 1, p. xi-xxxii, 2009.

Bailleau, Francis. La justice pénale de mineurs en France ou l'émergence d'un nouveau modèle de gestión des illégalismes. Déviance et Société, v. 26, n. 3, p. 403-421, 2002.

Bailleau, Francis; Carturvels, Yves. Les évolutions de la justice des mineurs en Europe: quelques hypothèses d'analyse. Revue de l'AFMJF, pp. 135-1402, 2007.

BRAsil, Código de Menores (1979). Lei Federal No 6.697, 10 de outubro de 1979. Disponível em: http://www.planalto.gov.br/ccivil_03/leis/1970-1979/L6697impressao.htm (Acesso em: 24 de julho de 2017)

BRASIL, Código de Menores (1927). Decreto No 17.943-A de 12 de outubro de 1927. Disponível em: http://www.planalto.gov.br/ccivil_03/decreto/1910-1929/D17943Aimpressao. htm (Acesso em: 24 de julho de 2017)

Brasil, Estatuto da Criança e do Adolescente (1990). Lei Federal 8.069 de 13/07/1990. Disponível em: http://www.planalto.gov.br/ccivil_03/leis/L8069.htm (Acesso em: 24 de julho de 2017)

Cicourel, Aaron V. The social organization of juvenile justice. New York: John Wiley \& Sons, Inc., 1968.

CAStro, Paulo Roberto de Andrade. A construção social do delinquente menor de idade na esfera jurídica. Universidade Federal Fluminense. Centro de Estudos Gerais. Programa de Pós-Graduação em Sociologia e Direito. Dissertação (mestrado). Niterói, 2006.

DinIz, Aline Pereira. O discurso psicológico nos pareceres sobre adolescentes com medida judicial de internação. Fundação Oswaldo Cruz. Escola Nacional de Saúde Pública. Dissertação (mestrado). Rio de Janeiro, 2001.

FeLD, Barry C. Abolish the juvenile court: youthfulness, criminal responsability, and sentencing policy. Journal of Criminal Law and Criminology. Vol. 88, n. 1, 1997.

FRASSETO, Flávio Américo. A execução da medida socioeducativa de internação: primeiras linhas de uma crítica garantista. In: Ilanud; Aвmp; Sedh; UnfPa (Org.). Justiça adolescente e ato infracional: socioeducação e responsabilização. São Paulo: ILANUD, 2006.

Avaliação psicológica em adolescentes privados da liberdade: uma crítica à execução da medida de internação. Universidade de São Paulo. Instituto de Psicologia. Dissertação (mestrado), 2005.

Garfinkel, Harold. Studies in ethnomethodology. Englewood Cliffs, NJ: Prentice-Hall, 1967. GARFInKEL, Harold; Lynch, Michael; Livingston, Eric. "I. 1 The Work of a Discovering Science Construed with Materials from the Optically Discovered Pulsar." Philosophy of the social sciences, v. 11, n. 2, 1981, pp. 131-158. 
Goffman, Erving. The presentation of self in everyday life. London: Penguin Books, 1990. Hull, Mathew. Documents and bureaucracy. Annual Review of anthropology, v. 41, pp. 251-267, 2012.

Lima, Juliana Vinuto. Entre o 'Recuperável' e o 'Estruturado': classificações dos funcionários de medida socioeducativa de internação acerca do adolescente em conflito com a lei. Universidade de São Paulo. Faculdade de Filosofia, Letras e Ciências Humanas. Departamento de Sociologia. Programa de Pós-Graduação em Sociologia. Dissertação (mestrado). São Paulo, 2014.

Machado, Martha de Toledo. Sistema especial de proteção da liberdade do adolescente na constituição de 1988 e no estado da criança e do adolescente. In: ILANUD; ABMP; SEDH; UNFPA (Org.). Justiça adolescente e ato infracional: socioeducação e responsabilização. São Paulo: ILANUD, 2006.

Méndez, Emilio García; Carranza, Elías. Del reves al derecho: la condicion jurídica de la infância em américa latina. Bases para uma reforma legislativa. Buenos Aires: Unicef/ UNICRI / ILANUD/ Editorial Clerna, 1992.

Méndez, Emilio García. "Evolução histórica do Direito da Infância e da Juventude”. In: ILANUD; ABMP; SEDH; UNFPA (Orgs.). Justiça adolescente e ato infracional: socioeducação e responsabilização. São Paulo: ILANUD, 2006.

Morrison, Kenneth L. "III. 1 Some Properties of 'Telling-Order Designs' in Didactic Inquiry." Philosophy of the Social Sciences, v. 11, n. 2, p. 245-262, 1981.

Mosqueira, Sáshenka Meza. A demanda por avaliação psicológica de adolescentes infratores: reflexões a partir de narrativas de atores da Justiça Juvenil e de psicólogas de Equipe Técnica do Juízo. Universidade de São Paulo. Instituto de Psicologia. Tese (doutorado). São Paulo, 2013.

Oliveira, Thiago Rodrigues; Lima, Juliana Vinuto; Alvarez, Marcos César. Gênero e medidas socioeducativas: uma análise das pastas e prontuários do "Complexo do Tatuapé”. In: Anais do IV Seminário Nacional de Estudos Prisionais, 2014.

OliveIRA, Thiago Rodrigues. Mecanismos sociais de decisões judiciais: um desenho misto explicativo sobre a aplicação da medida socioeducativa de internação. 2016. Dissertação (Mestrado em Sociologia) - Faculdade de Filosofia, Letras e Ciências Humanas, Universidade de São Paulo, São Paulo, 2016.

PIÑERo, Verónica B. The semantics of repression: linking, opposing, and linking again rehabilitation and protection of society. Revue Générale de Droit, v. 36, p. 189-263, 2006.

Platt, Anthony M. Los ‘Salvadores del Niño’ o la invención de la delincuencia. Coyoacán: Siglo Veintiuno Editores, 1997. 
RAWLS, Anne Warfield. "Orders of interaction and intelligibility: intersections between Goffman and Garfinkel by way of Durkheim” In: Treviño, A. Javier. Goffman's Legacy. Lanham: Rowman \& Littlefield Publishers, 2003.

Riles, Annelise. Introduction: in response. In: Riles, Annelise (Org.) Documents: artifacts of modern knowledge. Ann Arbor: The University of Michigan Press, 2006.

Rızzını, Irene; Rızzını, Irma. A institucionalização de crianças no Brasil: Percurso histórico e desafios do presente. Rio de Janeiro, São Paulo: Editora PUC-Rio, Loyola, 2004.

RodRigues, Gutemberg. Os filhos do mundo: a face oculta da menoridade (1964-1979). São Paulo: IBCCrim, 2001.

SARTório, Alexsandra Tomazelli; Rosa, Edinete Maria. Novos paradigmas e velhos discursos: analisando processos de adolescentes em conflito com a lei. Serviço Social \& Sociedade, São Paulo, n. 103, p. 554-575, jul./set. 2010.

Sснuсн, Patrice. Práticas de Justiça: uma etnografia do "Campo de Atenção ao Adolescente Infrator" no Rio Grande do Sul, depois do Estatuto da Criança e do Adolescente. UFRGS, Instituto de Filosofia e Ciências Humanas. Programa de Pós-Graduação em Antropologia Social (Tese de doutorado), 2005.

Sмiтн, Dorothy. Texts, facts, and femininity: exploring the relations of ruling. New York: Routledge, 1993.

TRÉPANIER, Jean. Juvenile Courts after 100 years: past and present orientations. European Journal on Criminal Policy and Research, n. 7, pp. 303-327, 1999.

WhitAKER, Christiane. O campo infracional: sistema de justiça e a prática judiciária à luz da psicanálise. São Paulo: Casa do Psicólogo, 2010.

Zimmerman, Don H. Fact as a practical accomplishment. In: Turner, Roy. Ethnomethodology: selected readings. Harmondsworth: Penguin Education, pp. 128-143, 1974. 